UCRL-ID-115456

\title{
Radiation Hardened Telerobotic Dismantling System: A Proposal for Remediating the UKRITYE Encasement at the Chernobyl NPP
}
A. Dougan
R. Kane
J. Pence
B. Wheeler
J. Wolford

May 1993

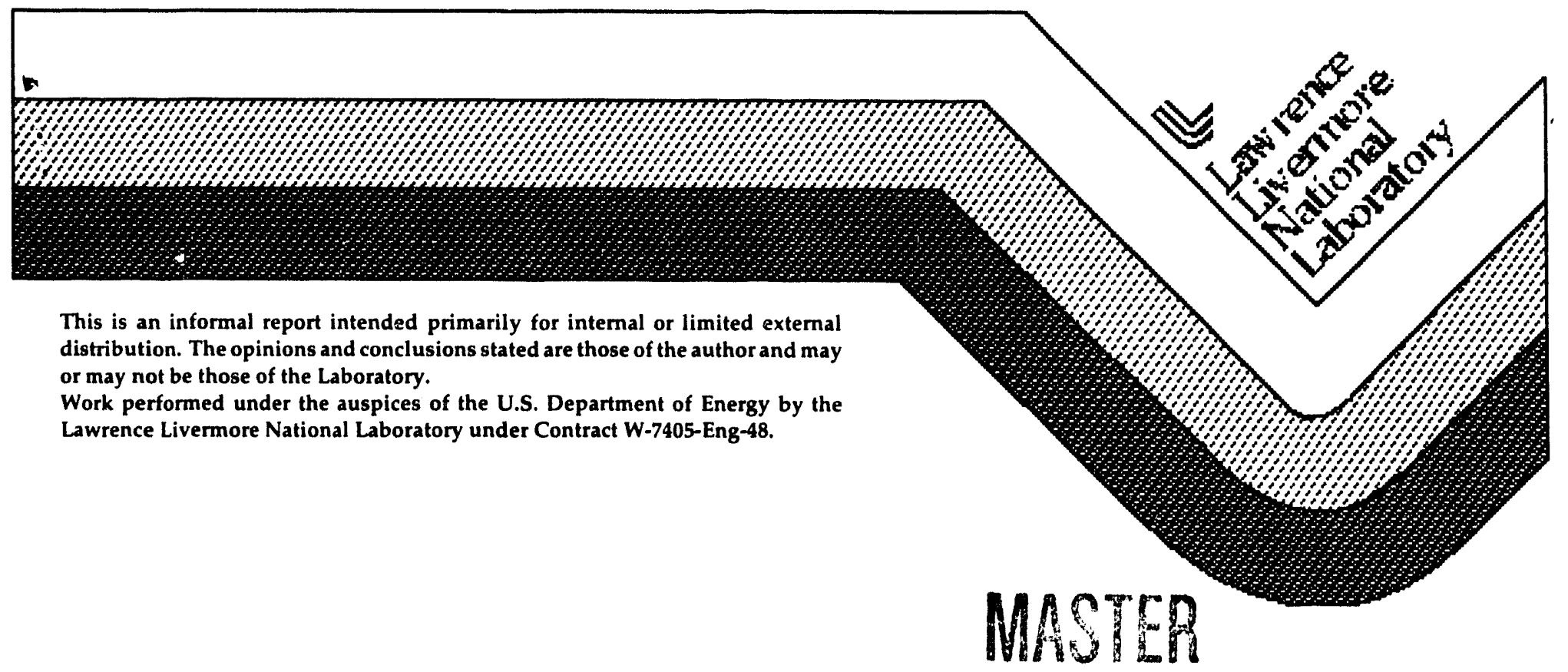




\section{DISCLAIMER}

This document was prepared as an account of work sponsored by an agency of the United States Government. Neither the United States Government nor the University of California nor any of their employees, makes any warranty, express or implied, or assumes any legal liability or responsibility for the accuracy, completeness, or usefulness of any information, apparatus, product, or process disclosed, or represents that its use would not infringe privately owned rights. Reference herein to any specific commercial products, process, or service by trade name, trademark, manufacturer, or otherwise, does not necessarily constitute or imply its endorsement, recommendation, or favoring by the United States Government or the University of California. The views and opinions of authors expressed herein do not necessarily state or reflect those of the United States Government or the University of California, and shall not be used for advertising or product endorsement purposes.

This report has been reproduced directly from the best available copy.

Available to DOE and DOE contractors from the Office of Scientific and Technical Information

P.O. Box 62, Oak Ridge, TN 37831

Prices available from (615) 576-8401, FTS 626-8401

Available to the public from the

National Technical Information Service

U.S. Department of Commerce 5285 Port Royal Rd.,

Springfield, VA 22161 
A major problem facing those charged with reclaiming the UKRITIYE encasement is the dismembering and removal of the fuel containing masses (FCMs). Due to the intense radiation fields involved, the work must be controlled remotely, so as to minimize exposure to humans. Radiation also quickly damages key components of conventional robots, and thus a successful design must eliminate these vulnerabilities. The inaccessibility of many work locations requires that the system either be able to maneuver around obstructions, or to cut and clear these obstructions itself.

We propose to design and construct a robotic knife to cut through obstructions and reactor debris, including FCMs. To withstand the severe radiation fields typical of high level waste, the robotic system will not rely on electrical motors or actuators, but will utilize pneumatic power for its manipulating and control functions. A pneumatic system would be far less susceptible to failure than an electrical or hydraulic one would. The system will use borated or chlorinated water with an abrasive as a cutting agent. The presence of boron or chlorine will minimize any possible criticality hazard in the vicinity of the FCMs due to water, which will nevertheless be small in volume. The design would minimize the number of moving parts and use dry bearings which are unaffected by high flux fields.

Due to its lack of vulnerability to high radiation fields, we propose using a water knife to slice up the large FCMs. Water knives in operation at this laboratory are capable of blind hole cutting rates of approximately $8 \mathrm{~cm} /$ minute in $15 \mathrm{~cm}$ thick vitrified material. Cutting rates for non-blind cuts are approximately twice this figure. We believe that by optimizing the fluid and nozzle parameters for this application, we can enhance these cutting rates by $10-50 \%$. The system consumes approximately 4 liters of water and 0.6 kilograms of abrasive per minute. The system will use borated or chlorinated water to minimize any possible criticality hazard in the vicinity of the FCMs due to neutron reflection. We will design into the system a water recovery feature which will minimize the introduction of new waste water which will nevertheless be low in volume.

In order to view and operate the knife, we will design and build a hardened video camera system. In general, the cameras will be located as far from the FCMs as possible while still serving their purpose. They will be shielded from the intense radiation fields (up to $2000 \mathrm{R} / \mathrm{hr}$ expected) using uranium or tungsten enclosures to extend their operational lifetimes to at least 40 hours. Where possible, the cameras will be isolated from direct lines of sight via polished metal mirrors. If a direct line of sight is necessary, the camera will be collimated using a pinhole through the shielded enclosure. The design of the housings will permit fast and easy replacement of the compact camera modules.

The robot will be tethered via flexible, metallic conduit to a control console which will supply the vehicle with high pressure water for cutting, as well as lower pneumatic pressures for automation and command and control signals. The control console will be located at a safe remote location, providing complete control of the vehicle. A shielded cable within the conduit will transmit video 
images. The conduit will also serve as a track to guide a shielded gondola into and out of the high radiation area. This gondola cart will shuttle back and forth carrying FCM fragments to a staging area. As an alternative, the robot could be fitted with a pneumatic impact tool to pulverize the FCM fragments into a slurry which could be siphoned away.

We will consider adding tools based on other cutting technologies as operational constraints permit. For instance, a pneumatic core drill, approximately $15 \mathrm{~cm}$ in diameter, could supply samples for monitoring the structure and composition of the FCM as a function of position. Core drilling would require less liquid and produce less waste for those masses of material with sufficient access.

We will use any available information about the presence and orientation of obstructions to optimize the design of the system. If indicated, a computer model will be developed to simulate the navigation of the robot within the UKRITIYE encasement. Estimates of the radiation field intensity will determine shielding requirements for vulnerable components, such as the cameras.

Technical Contact: Dr. Mark S. Rowland, LLNL, 510/42302003 


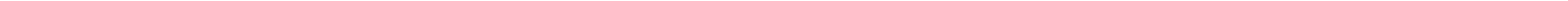


